BMJ Open

Diabetes

Research

$\&$ Care

\section{Increased stress, weight gain and less exercise in relation to glycemic control in people with type 1 and type 2 diabetes during the COVID-19 pandemic}

To cite: Ruissen MM, Regeer $\mathrm{H}$, Landstra CP, et al. Increased stress, weight gain and less exercise in relation to glycemic control in people with type 1 and type 2 diabetes during the COVID-19 pandemic. BMJ Open Diab Res Care 2021:9:e002035. doi:10.1136/ bmjdrc-2020-002035

- Supplemental material is published online only. To view, please visit the journal online (http://dx.doi.org/10.1136/ bmjdrc-2020-002035).

Received 23 November 2020 Revised 2 December 2020 Accepted 5 December 2020

Check for updates

C Author(s) (or their employer(s)) 2021. Re-use permitted under CC BY-NC. No commercial re-use. See rights and permissions. Published by BMJ.

For numbered affiliations see end of article.

Correspondence to Professor Eelco J P de Koning; E.J.P.de_Koning@lumc.nl

\section{ABSTRACT}

Introduction Lockdown measures have a profound effect on many aspects of daily life relevant for diabetes selfmanagement. We assessed whether lockdown measures, in the context of the COVID-19 pandemic, differentially affect perceived stress, body weight, exercise and related this to glycemic control in people with type 1 and type 2 diabetes.

Research design and methods We performed a shortterm observational cohort study at the Leiden University Medical Center. People with type 1 and type 2 diabetes $\geq 18$ years were eligible to participate. Participants filled out online questionnaires, sent in blood for hemoglobin A1c ( $\mathrm{HbA1c})$ analysis and shared data of their flash or continuous glucose sensors. HbA1c during the lockdown was compared with the last known $\mathrm{HbA1c}$ before the lockdown.

Results In total, 435 people were included (type 1 diabetes $n=280$, type 2 diabetes $n=155$ ). An increase in perceived stress and anxiety, weight gain and less exercise was observed in both groups. There was improvement in glycemic control in the group with the highest $\mathrm{HbA1c}$ tertile (type 1 diabetes: $-0.39 \%(-4.3 \mathrm{mmol} / \mathrm{mol})(\mathrm{p}<0.0001$ and type 2 diabetes: $-0.62 \%(-6.8 \mathrm{mmol} / \mathrm{mol})(p=0.0036)$.

Perceived stress was associated with difficulty with glycemic control $(p<0.0001)$.

Conclusions An increase in perceived stress and anxiety, weight gain and less exercise but no deterioration of glycemic control occurs in both people with relatively well-controlled type 1 and type 2 diabetes during shortterm lockdown measures. As perceived stress showed to be associated with glycemic control, this provides opportunities for healthcare professionals to put more emphasis on psychological aspects during diabetes care consultations.

\section{INTRODUCTION}

The COVID-19 pandemic is a major healthcare crisis and has a major impact on daily life worldwide. With currently no vaccine or treatment available, this viral pandemic results in a rapid increase in morbidity and mortality

\section{Significance of this study}

What is already known about this subject?

- Lockdown measures affect many aspects of daily life that are relevant for diabetes self-management, while access to diabetes care is changed.

What are the new findings?

- In people with type 1 and type 2 diabetes lockdown measures during the COVID-19 pandemic resulted in increased stress and anxiety, weight gain and less exercise.

- Despite these changes, no deterioration in glycemic control was present.

- Increased stress was associated with difficulty in glycemic control.

How might these results change the focus of research or clinical practice?

- Diabetes care professionals should take the psychological impact of lockdown measures into account when discussing diabetes self-management and well-being during consultations.

rates. So far over 63 million cases have been confirmed, resulting in almost 1.5 million deaths worldwide. ${ }^{1}$

Mortality rates from COVID-19 are highest in elderly people. ${ }^{2}$

Also people with diabetes mellitus have been identified to be at increased mortality risk. ${ }^{2}$ Often no distinction is made between type 1 diabetes and type 2 diabetes. But as other risk factors for adverse outcomes of COVID-19 such as elderly age, obesity, hypertension and cardiovascular disease are very prevalent in type 2 diabetes, people with this diabetes subtype are considered to be at even higher risk. ${ }^{3}$ 
In an attempt to control the outbreak, many countries implemented lockdown measures. ${ }^{4}$ Lockdown strategies diverged from lockdown of cities, regions or countries to voluntary home curfews, travel restrictions and prohibition of public and social events. ${ }^{5}$ These measures resulted in major changes in daily life and social behavior. Such sudden and major disruptions in everyday life are known to influence both physical and mental health. ${ }^{6}$

The alterations in behavioral patterns, daily life and exercise as well as increased feelings of stress and anxiety are all known to influence diabetes self-management and glycemic control. ${ }^{7-14}$ Also a change in diabetes care by health professionals further increased the importance of adequate self-management behavior of people with diabetes mellitus. Thus, several factors coincided that challenged maintenance of glycemic control during the lockdown measures. It is unclear how the lockdown has a differential impact on people with type 1 and type 2 diabetes and whether the presence of additional risk factors for severe outcomes of COVID-19 in these people plays a role.

\section{METHODS}

People with type 1 and type 2 diabetes that were treated at the diabetes outpatient clinic of the Leiden University Medical Center were invited to participate. Other inclusion criteria were age $\geq 18$ years, sufficient comprehension of the Dutch language and ability to perform fingerpricks and complete an online supplemental questionnaire. People that were pregnant, recently $(\leq 6$ months) diagnosed with a malignancy, receiving immunotherapy or chemotherapy or admitted to a hospital or rehabilitation centre were excluded from participation.

\section{Lockdown period and measures taken}

Lockdown measures were implemented in the Netherlands on 15 March 2020 by the government. These measures included stay-at-home orders for people working in non-vital areas of society, social distancing and closures of schools, restaurants, bars and public spaces. A sudden reduction in mobility around the workplace $(40 \%)$ and in the context of retail and recreation $(40 \%)$ and an increase in mobility around residential grounds (20\%) occurred immediately after March 15 as shown by mobility data of the Dutch population validating the effect of the lockdown measures. ${ }^{15}$ Because of the measures taken and the results of the mobility data, March 15 was considered the start of the lockdown period. Data were collected 8-11 weeks after the start of the lockdown period. During the entire data collection period, the lockdown measures were maintained.

\section{Assessment of the impact of the lockdown period}

After informed consent was provided, participants received a link to the online supplemental questionnaire via email. The online supplemental questionnaire consisted of multiple items to assess the impact of the lockdown on glycemic control and medication use, daily routines, physical activity and psychological stress, including the 'Perceived Stress Scale'. ${ }^{16}$

A hemoglobin A1c (HbA1c) fingerprick set was sent to the participant's home in order to prevent visits to the hospital. This set consists of a small tube, a lancet and a return medical envelope. Via a fingerprick a small amount of capillary blood was collected in a tube by patients at home, which was then sent to the hospital laboratory by mail. ${ }^{17}$ This is a validated and well-established measuring method for HbAlc analysis, providing identical results compared with HbAlc measurements in venous blood samples. ${ }^{18}$

HbA1c 8-11 weeks (interval median (IQR) 65 (61-71) days) after the start of the lockdown period was compared with the last known HbAlc before 15 March 2020 (interval median (IQR) 178 (137-218) days before the start of the lockdown).

For people with type 1 diabetes using a continuous glucose monitor (CGM) or flash glucose monitor (FGM) data were analysed during 2 weeks before the lockdown period (24 February until 8 March) and 6 weeks after the start of the lockdown period (24 April until 7 May). Online data sharing platforms were used to gain access to those data. If participants were on holiday during one or both of these weeks prior to the lockdown period, they provided the data of two adjacent regular weeks prior to the lockdown period. As a recent start of FGM or CGM can improve glycemic control, people who had started CGM or FGM within 2 months of the start of the lockdown period were excluded from glucose sensor data and HbAlc analysis. CGM or FGM data were used to calculate time below range ( $\%$ of time glucose $<4.0 \mathrm{mmol} / \mathrm{L}$ ), time in range ( $\%$ of time glucose $4.0-10.0 \mathrm{mmol} / \mathrm{L}$ ), time above range ( $\%$ of time glucose $\geq 10.0 \mathrm{mmol} / \mathrm{L}$ ), the coefficient of variation $(\% \mathrm{CV})$, the time of active use (\% of time) and the average number of scans per day (n).

\section{Statistical analysis}

Differences in questionnaire outcomes between people with type 1 and type 2 diabetes were analysed using $\chi^{2}$ tests. The change in glycemic control was analysed by paired t-tests. Differences in change in HbA1c between people with type 1 diabetes and type 2 diabetes were analysed using unpaired t-tests. Regression analyses were used to assess associations between glycemic parameters, body mass index (BMI) and outcomes on lifestyle, insulin use, glucose regulation and stress. CIs of the regression coefficients are reported. People were divided into tertiles based on their HbAlc prior to the lockdown period and associations with questionnaire outcomes were analysed using ordinal logistical regression analysis. We performed complete case analyses. STATA V.14.2 was used to perform the analyses.

\section{RESULTS}

A total of 435 participants ( $42 \%$ female) were included (type 1 diabetes $n=280$, type 2 diabetes $n=155$ ) (table 1 ). A 
Table 1 Baseline characteristics

\begin{tabular}{|c|c|c|}
\hline & $\begin{array}{l}\text { Type } 1 \\
\text { diabetes } \\
(n=280)\end{array}$ & $\begin{array}{l}\text { Type } 2 \\
\text { diabetes } \\
(n=155)\end{array}$ \\
\hline Age, mean (SD), years & $50.1( \pm 14.9)$ & $62.5( \pm 11.6)$ \\
\hline Sex, $\mathrm{n}(\%)$, female & $129(46.1)$ & $54(34.8)$ \\
\hline BMI, mean (SD), kg/m² & $25.9( \pm 4.3)$ & $30.2( \pm 6.1)$ \\
\hline \multicolumn{3}{|l|}{ Level of education, $\mathrm{n}(\%)^{*}$} \\
\hline Low & $9(3.4)$ & $4(3.0)$ \\
\hline Middle & $98(37.0)$ & $73(54.5)$ \\
\hline High & $158(59.6)$ & $57(42.5)$ \\
\hline \multicolumn{3}{|l|}{ Living situation, n (\%) } \\
\hline Alone & $41(15.5)$ & $23(17.2)$ \\
\hline Co-habitating & $242(84.5)$ & $111(82.8)$ \\
\hline $\begin{array}{l}\text { Duration of diabetes, mean (SD), } \\
\text { years }\end{array}$ & $27.5( \pm 15.1)$ & $15.8( \pm 9.3)$ \\
\hline \multicolumn{3}{|l|}{ Glucose-lowering medication, n (\%) } \\
\hline None & $1(0.4)$ & $6(4.0)$ \\
\hline Metformin & $11(4.0)$ & $105(67.7)$ \\
\hline SGLT-2 inhibitors & $0(0.0)$ & $15(9.7)$ \\
\hline Sulfonylurea derivatives & $1(0.4)$ & $38(24.5)$ \\
\hline GLP-1 receptor antagonists & $1(0.4)$ & $25(16.1)$ \\
\hline Basal insulin only & $8(3.0)$ & $25(18.9)$ \\
\hline Basal-bolus insulin regimen & $256(96.6)$ & $49(37.1)$ \\
\hline \multicolumn{3}{|l|}{ Glucose monitoring, n (\%) } \\
\hline None & $3(1.1)$ & $29(21.6)$ \\
\hline Blood glucose monitoring only & $62(23.4)$ & $91(67.9)$ \\
\hline $\begin{array}{l}\text { Flash or continuous glucose } \\
\text { monitoring }\end{array}$ & $200(75.5)$ & $14(10.5)$ \\
\hline \multicolumn{3}{|l|}{ Complications, n (\%) } \\
\hline None & $58(20.7)$ & $21(13.6)$ \\
\hline Retinopathy & $189(68.2)$ & $86(56.2)$ \\
\hline Laser coagulation & $61(22.1)$ & $19(12.5)$ \\
\hline $\mathrm{GFR} \geq \mathrm{G} 2 \dagger$ & $120(44.4)$ & $92(67.7)$ \\
\hline Albuminuria (A1-A3) & $27(12.2)$ & $33(30.6)$ \\
\hline Peripheral neuropathy & $69(25.4)$ & $62(40.0)$ \\
\hline Cardiovascular complicationsł & $66(23.9)$ & $77(49.7)$ \\
\hline Kidney transplantation, n (\%) & $3(1.1)$ & $3(1.9)$ \\
\hline \multicolumn{3}{|l|}{ Blood pressure, mean (SD), mm Hg } \\
\hline Systolic blood pressure & $133( \pm 18)$ & $138( \pm 17)$ \\
\hline Diastolic blood pressure & $78( \pm 8)$ & $79( \pm 9)$ \\
\hline \multicolumn{3}{|c|}{ Blood pressure-lowering medication, n (\%) } \\
\hline None & $171(61.7)$ & $45(29.0)$ \\
\hline ACE inhibitors & $59(21.3)$ & $41(26.5)$ \\
\hline Angiotensin receptor blockers & $25(9.0)$ & $43(27.7)$ \\
\hline Calcium antagonists & $36(13.0)$ & $232(20.7)$ \\
\hline Alpha blockers & $5(1.8)$ & $15(9.7)$ \\
\hline Beta blockers & 30 (10.8) & 50 (32.3) \\
\hline Diuretics & $39(14.1)$ & 38 (24.5) \\
\hline
\end{tabular}

Continued
Table 1 Continued

\begin{tabular}{|c|c|c|}
\hline & $\begin{array}{l}\text { Type } 1 \\
\text { diabetes } \\
(n=280)\end{array}$ & $\begin{array}{l}\text { Type } 2 \\
\text { diabetes } \\
(n=155)\end{array}$ \\
\hline $\begin{array}{l}\text { Mineralocorticoid receptor } \\
\text { antagonists }\end{array}$ & $7(2.5)$ & $4(2.6)$ \\
\hline $\begin{array}{l}\text { LDL cholesterol, mean (SD), } \\
\mathrm{mmol} / \mathrm{mol}\end{array}$ & $2.41( \pm 0.78)$ & $2.25( \pm 1.01)$ \\
\hline \multicolumn{3}{|l|}{ Lipid-lowering medication, n (\%) } \\
\hline None & $164(59.2)$ & $61(39.4)$ \\
\hline Statins & $109(39.4)$ & $92(59.7)$ \\
\hline Ezetimibe & $11(4.0)$ & $11(7.1)$ \\
\hline \multicolumn{3}{|l|}{ Smoking, n (\%) } \\
\hline No & $239(89.5)$ & $126(88.7)$ \\
\hline Occasional§ & $7(2.6)$ & $3(2.1)$ \\
\hline Regularף & $21(7.9)$ & $13(9.2)$ \\
\hline \multicolumn{3}{|l|}{ Pulmonary comorbidities, n (\%) } \\
\hline Asthma, COPD or lung fibrosis & $16(5.8)$ & $20(12.9)$ \\
\hline \multicolumn{3}{|l|}{ Other medication, $\mathrm{n}(\%)$} \\
\hline Immunosuppressive agents & $14(5.1)$ & $13(8.4)$ \\
\hline Antidepressive agents & $17(6.2)$ & $12(7.7)$ \\
\hline
\end{tabular}

${ }^{\star}$ Education: low (elementary school), intermediate (elementary school plus high school and practical education), high (college or university).

† Measure for chronic kidney function, GFR $\geq \mathrm{G} 2=\mathrm{GFR} \leq 89 \mathrm{~mL} /$ $\min / 1.73 \mathrm{~m}^{2}{ }^{28}$

$\ddagger$ Myocardial infarction/PCl/peripheral vascular disease/stroke/ $\mathrm{TIA} /$ heart failure or amputation of toe/foot/leg.

§Occasional smoking $\geq 1 \times /$ week. $^{29}$

१Regular smoking $\geq 1 \times /$ day. ${ }^{29}$

BMI, body mass index; COPD, chronic obstructive pulmonary disease; GFR, glomerular filtration rate; GLP-1, glucagon-like peptide-1; LDL, low-density lipoprotein; ; $\mathrm{PCl}$, percutaneous coronary intervention; SGLT-2, sodium-glucose cotransporter-2; TIA, transient ischemic attack.

basal-bolus regimen was used by $76.8 \%$ and basal insulin only by $8.3 \%$ of people. People with type 2 diabetes were on average 12.3 years older and had a higher BMI (table 1). The prevalence of cardiovascular complications, elevated systolic blood pressure and use of blood pressure-lowering agents was higher in people with type 2 diabetes (table 1 ).

\section{Stress, weight change and exercise}

In total, 399 participants completed the questionnaire on daily routines, physical activity, psychological stress and participant's glycemic control and medication use (online supplemental table 1).

During self-lockdown $34.1 \%$ of all participants reported elevated stress (figure 1), without any difference between people with type 1 and type 2 diabetes (33.6\% vs $35.1 \%$, Perceived Stress Score: $13.7( \pm 6.2)$ vs $12.8( \pm 6.7)$, respectively). A change in perceived stress was associated with a change in HbA1c (95\% CI 0.015 to $0.38, \mathrm{p}=0.034$ ). People who reported more difficult glycemic control 

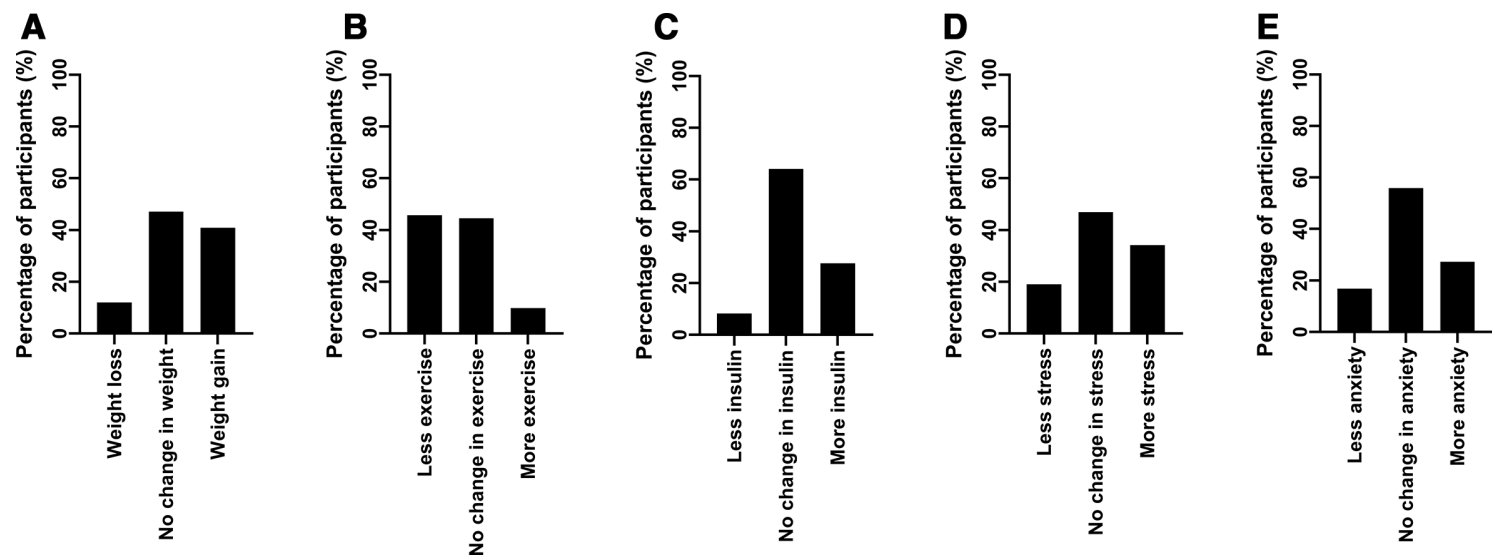

Figure 1 Change in self-reported weight (A), exercise (B), insulin use (C), perceived stress (D) and anxiety (E) during the lockdown period. (A) Weight loss: sum of percentage of participants in different categories of weight loss (online supplemental table 1). Weight gain: sum of percentage of participants in different categories of weight gain (online supplemental table 1). (C) Less insulin: sum of percentage of participants in different categories of less insulin use. More insulin: sum of percentage of participants in different categories of more insulin use. (D) Less stress: sum of percentage of participants in categories of less stress. More stress: sum of percentage of participants in different categories of more stress. (E) Less anxiety: sum of percentage of participants in different categories of less anxiety. More anxiety: sum of percentage of participants in different categories of more anxiety.

experienced higher stress during the lockdown period (95\% CI 0.41 to $0.83, \mathrm{p}<0.0001)$ and needed more insulin than before the lockdown period (95\% CI 1.35 to 2.08, $\mathrm{p}<0.0001)$. Furthermore, $27.3 \%$ of all participants reported elevated levels of anxiety (figure 1), without any difference between people with type 1 and type 2 diabetes $(27.5 \%$ vs $26.9 \%)$. Anxiety for COVID-19 infection was not associated with the change in HbAlc.

Furthermore, $40.9 \%$ of the participants reported weight gain and $45.7 \%$ reported less exercise than before (figure 1). Only $12 \%$ of the participants reported a loss of weight and $10 \%$ of the participants reported more exercise. Less exercise was associated with weight gain during the period of self-lockdown $(p<0.0001)$. The change in exercise or weight gain was not associated with the change in HbA1c ( $95 \%$ CI -0.20 to $0.05, \mathrm{p}=0.25$ and $95 \%$ CI -0.002 to $0.39, \mathrm{p}=0.053$, respectively).

\section{Impact of lockdown measures on glycemic control}

HbA1c was slightly lower in people with type 1 diabetes in the lockdown period (pre-lockdown $7.68 \% \pm 1.2$ $(60.4 \pm 12.7 \mathrm{mmol} / \mathrm{mol}) \quad$ vs lockdown $7.52 \% \pm 1.1$ $(58.7 \pm 12.2 \mathrm{mmol} / \mathrm{mol}), \mathrm{p}<0.0001)$ but not in people with type 2 diabetes (figure 2A). Glucose monitoring data reflected this improvement in HbAlc in people with type 1 diabetes. Time in range was higher (pre-lockdown $60.5 \%$ vs lockdown $63.4 \%, \mathrm{p}=0.0009$ ) and time above range was lower (pre-lockdown $34.6 \%$ vs lockdown $32.1 \%$, $\mathrm{p}<0.003$ ) (figure 2B). Glucose variability did not change. There was more frequent active glucose monitoring with an increase in the number of FGM scans per day (prelockdown $9.6( \pm 6.5)$ vs lockdown $11.8( \pm 8.1)$ scans/day, $95 \%$ CI -3.81 to $-0.58, \mathrm{p}<0.01)$ in people with type 1 diabetes indicating more focus on self-management.

Both people with type 1 and type 2 diabetes that were in the highest pre-lockdown tertile of HbAlc (type 1 diabetes: HbA1c 8.13\%-12.18\%, type 2 diabetes: HbA1c $8.16 \%-12.72 \%$ ) showed improvement in HbA1c (type 1 diabetes: $-0.39 \%, 95 \%$ CI 0.22 to $0.55 \%$, $\mathrm{p}<0.0001$, type 2 diabetes: $-0.62 \%, 95 \%$ CI 0.22 to $1.03 \%, \mathrm{p}=0.0036$ ) (figure 2C). Proportionally more people with type 1 diabetes in the highest HbAlc tertile group showed improvement in HbA1c compared with people with type 2 diabetes in that tertile (figure 2D).

\section{Risk factors for a more severe outcome of COVID-19}

BMI, presence of cardiovascular disease, systolic blood pressure or use of blood pressure-lowering agents was not associated with a change in stress or HbAlc during the lockdown period.

\section{DISCUSSION}

People with diabetes mellitus are considered a highrisk population prone to a complicated course of COVID-19 and associated mortality. ${ }^{19}$ Here, we show that in people with relatively well controlled type 1 and type 2 diabetes the COVID-19 pandemic and lockdown measures increased stress and resulted in weight gain and less physical exercise during this short observational period. However, despite these factors no deterioration in glycemic control was observed.

Previous research has shown a lockdown to be associated with increased levels of emotional distress and anxiety, ${ }^{56}$ which is in line with our findings. Distress, as well as changes in daily structures and behavior, which were inevitable due to the lockdown period, are known to influence diabetes self-management and glycemic control. ${ }^{7-10}$ Adding to this challenge of maintaining glycemic control was the increased emphasis on diabetes self-management due to a shift to COVID-19 care and social distancing rules in hospitals, which led to 
A

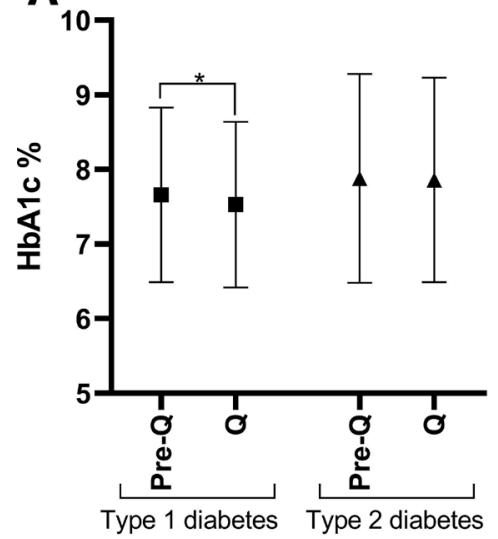

C

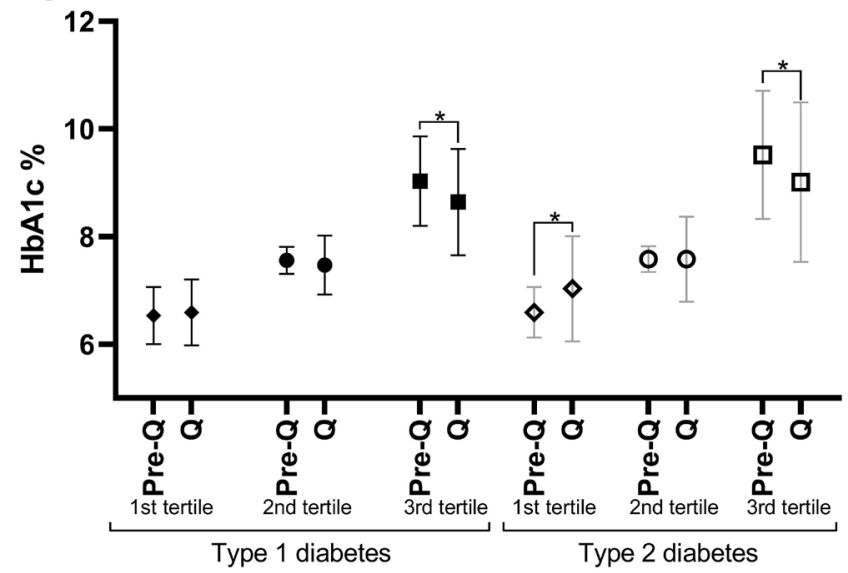

B

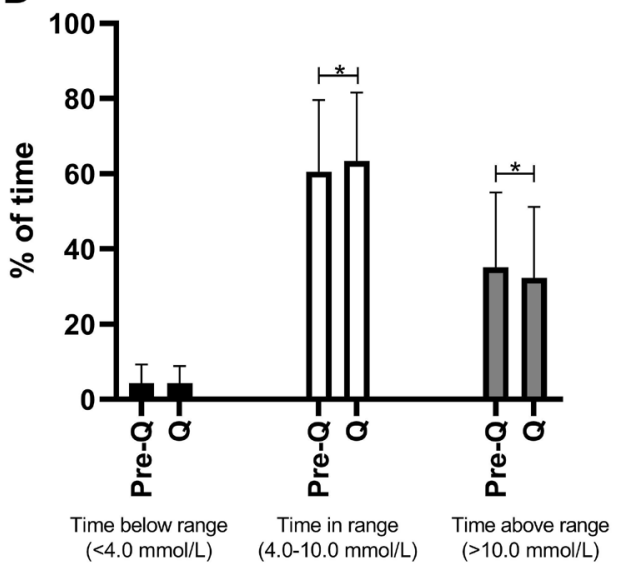

D

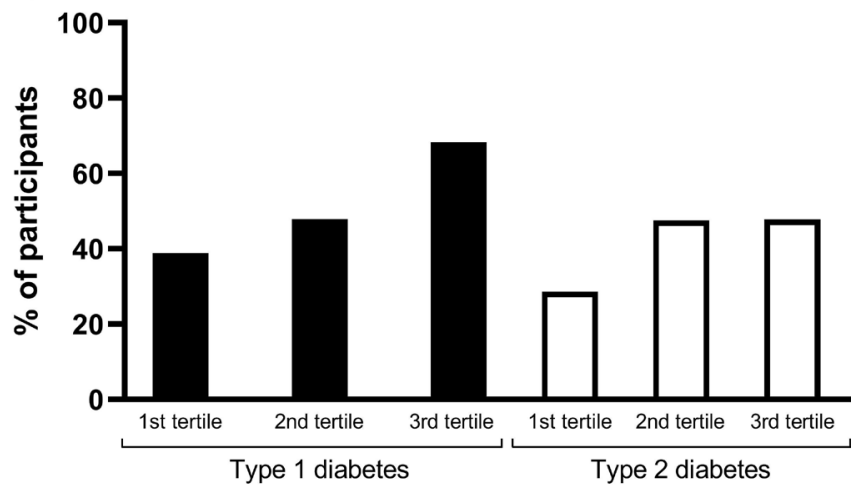

Figure 2 (A) Hemoglobin A1c (HbA1c) before the lockdown period (pre-Q) and during the lockdown period (Q) in people with type 1 diabetes and type 2 diabetes. (B) Ambulatory glucose profiles before and during the lockdown period in people with type 1 diabetes $(n=90)$. (C) HbA1c per tertile before (pre-Q) and during $(Q)$ the lockdown period in people with type 1 diabetes and type 2 diabetes. First tertile: type 1 diabetes mellitus (T1DM): HbA1c 4.92\%-7.22\%, type 2 diabetes mellitus (T2DM): 5.43\%-7.20\%; second tertile: T1DM: 7.23\%-8.09\%, T2DM: 7.23\%-8.02\%; third tertile: T1DM: HbA1c 8.13\%-12.18\%, T2DM: $\mathrm{HbA1c} 8.16 \%-12.72 \%$. (D) Percentage of people with type 1 and type 2 diabetes with improvement of HbA1c per tertile. $\mathrm{HbA1c}$ was available for 339 participants.

cancellations of face-to-face consultations, and the use of telemedicine. The small overall improvement in HbAlc in people with type 1 diabetes $(-0.16 \%)$ may be statistically significant but clinically not relevant. Together with an increase in scans of glucose sensors, these results indicate an increased focus on self-management. However, it should be noted that seasonal variation in glycemic control has been shown and higher temperatures are associated with lower HbAlc. ${ }^{20} 21$ Thus, the small improvement in glycemic control could be due to a seasonal variation in our and other studies. Our results also indicate that the presence of more risk factors for a severe outcome of COVID-19, such as a higher BMI, cardiovascular comorbidities and hypertension, was not associated with stress, anxiety or change in HbAlc.

One of the main strengths of our study is the large study population, consisting of both people with type 1 and type 2 diabetes. We were able to assess changes in psychological stress, body weight and exercise providing important insight in participant's daily life during the lockdown period and knowledge about potential opportunities for improvement of diabetes care. The large study population allowed us to investigate these factors both in people with good and poor glycemic control, and we used both HbAlc and glucose monitoring data. For people with type 1 diabetes, our findings are in line with flash glucose monitoring data in a small group of 55 people, in which a small improvement in time in range and time above range was observed. ${ }^{22}$

A limitation of the study is the reliance on self-reported data due to restricted access to health facilities during the lockdown period. Self-reported data about weight change are often an underestimation of the actual change in weight. ${ }^{23}$ So the proportion of participants that increased in weight may be even larger. Furthermore, while HbAlc reflects glycemic control during the previous 3 months, the lockdown period had only been going on for 8-11 weeks at the time that the HbAlc measurement was performed and may underestimate the impact of lockdown on glycemic control. It should also be noted that 
most of the people with diabetes who participated in the study were relatively well controlled. In addition, most participants with type 2 diabetes used insulin. Therefore, the results are not representative for all people with diabetes, especially for people with type 2 diabetes as the majority of them do not need insulin treatment and are treated in primary care.

Poor glycemic control is considered a risk factor for adverse outcomes of infections. ${ }^{24-26}$ Although no data are available, the message that poor glycemic control poses a higher risk is often conveyed to people in the context of COVID-19. ${ }^{27}$ We found a decrease of HbA1c in the group with the poorest glycemic control. People who experienced most difficulty with glycemic control also experienced more stress. Potentially, people with the poorest glycemic control may have put more emphasis on glycemic control in order to cope with the increased stress levels, ultimately improving their $\mathrm{HbA1c}$ values during the lockdown period. However, also for this subanalysis seasonal effects in HbAlc cannot be completely excluded.

In conclusion, our short-term observational study shows that lockdown measures resulted in increased levels of perceived stress, weight gain and less exercise in both people with relatively well-controlled type 1 and type 2 diabetes, however this did not negatively impact glycemic control. Additional risk factors for adverse outcomes of COVID-19, including poor glycemic control, do not appear to influence this effect. Since a third of the participants reported elevated levels of stress, associated with difficulties in glycemic control, diabetes care professionals should take these aspects into account when discussing diabetes self-management and well-being during consultations.

\section{Author affiliations \\ ${ }^{1}$ Department of Medicine, Division of Endocrinology, Leiden University Medical Center, Leiden, Zuid-Holland, The Netherlands \\ ${ }^{2}$ Department of Clinical Chemistry and Laboratory Medicine, Leiden University Medical Center, Leiden, Zuid-Holland, The Netherlands \\ ${ }^{3}$ Department of Epidemiology, Leiden University Medical Center, Leiden, Zuid- Holland, The Netherlands}

Acknowledgements The authors would like to thank the people from the outpatient hospital clinic of the LUMC for participating in the study.

Contributors MMR, HR, SDH and EJPdK designed the study and developed the methodology. MMR, HR and CPL coordinated the field work. MMR analyzed the data, wrote the manuscript and interpreted the results. HR, SDH and EJPdK reviewed the analysis, interpretations and manuscript and did the final review. $\mathrm{CPL}, \mathrm{MS}, \mathrm{IJ}, \mathrm{MFN}, \mathrm{HP}, \mathrm{BEPBB}$ and $\mathrm{OD}$ reviewed the analysis and manuscript. MMR is the guarantor of this work and, as such, had access to all data and takes responsibility for the integrity of the data and the accuracy of the data analysis.

Funding The authors have not declared a specific grant for this research from any funding agency in the public, commercial or not-for-profit sectors.

Competing interests None declared.

Patient consent for publication Not required.

Ethics approval This study was approved by the Medical Ethics Committee of Leiden, Den-Haag, Delft under the Medical Research Involving Human Subjects Act (WM0) prior to the start of the study (NL73778.058.20).

Provenance and peer review Not commissioned; internally peer reviewed.
Data availability statement Data are available on reasonable request. The data used in this article can be requested at the Leiden University Medical Center.

Supplemental material This content has been supplied by the author(s). It has not been vetted by BMJ Publishing Group Limited (BMJ) and may not have been peer-reviewed. Any opinions or recommendations discussed are solely those of the author(s) and are not endorsed by BMJ. BMJ disclaims all liability and responsibility arising from any reliance placed on the content. Where the content includes any translated material, BMJ does not warrant the accuracy and reliability of the translations (including but not limited to local regulations, clinical guidelines, terminology, drug names and drug dosages), and is not responsible for any error and/or omissions arising from translation and adaptation or otherwise.

Open access This is an open access article distributed in accordance with the Creative Commons Attribution Non Commercial (CC BY-NC 4.0) license, which permits others to distribute, remix, adapt, build upon this work non-commercially, and license their derivative works on different terms, provided the original work is properly cited, appropriate credit is given, any changes made indicated, and the use is non-commercial. See: http://creativecommons.org/licenses/by-nc/4.0/.

\section{ORCID iDs}

Marielle Schroijen http://orcid.org/0000-0001-8865-0224

Eelco J P de Koning http://orcid.org/0000-0002-1232-7022

\section{REFERENCES}

1 WHO. Coronavirus disease (COVID-19) pandemic, 2020. Available: https://www.who.int/emergencies/diseases/novel-coronavirus2019?gclid=EAlalQobChMlk7GEjp-L6gIVFomyCh3PAQznEAAYASA AEgKdrPD_BwE [Accessed 30 Nov 11 2020].

2 Yang J, Zheng Y, Gou X, et al. Prevalence of comorbidities and its effects in patients infected with SARS-CoV-2: a systematic review and meta-analysis. Int J Infect Dis 2020;94:91-5.

3 Gerich JE. Type 2 diabetes mellitus is associated with multiple cardiometabolic risk factors. Clin Cornerstone 2007;8:53-68.

4 Nussbaumer-Streit B, Mayr V, Dobrescu Al, et al. Quarantine alone or in combination with other public health measures to control COVID-19: a rapid review. Cochrane Database Syst Rev 2020;4:CD013574.

5 Hossain MM, Sultana A, Purohit N. Mental health outcomes of quarantine and isolation for infection prevention: a systematic umbrella review of the global evidence. Epidemiol Health 2020;42:e2020038.

6 Brooks SK, Webster RK, Smith LE, et al. The psychological impact of quarantine and how to reduce it: rapid review of the evidence. Lancet 2020;395:912-20.

7 Peyrot M, Rubin RR, Lauritzen T, et al. Psychosocial problems and barriers to improved diabetes management: results of the crossnational diabetes attitudes, wishes and needs (dawn) study. Diabet Med 2005;22:1379-85.

8 Gonder-Frederick LA, Carter WR, Cox DJ, et al. Environmental stress and blood glucose change in insulin-dependent diabetes mellitus. Health Psychol 1990;9:503-15.

9 Faulenbach $\mathrm{M}$, Uthoff $\mathrm{H}$, Schwegler $\mathrm{K}$, et al. Effect of psychological stress on glucose control in patients with type 2 diabetes. Diabet Med 2012;29:128-31.

10 Halford WK, Cuddihy S, Mortimer RH. Psychological stress and blood glucose regulation in type I diabetic patients. Health Psychol 1990;9:516-28.

11 Sardinha LB, Magalhães JP, Santos DA, et al. Sedentary patterns, physical activity, and cardiorespiratory fitness in association to glycemic control in type 2 diabetes patients. Front Physiol 2017;8:262.

12 Nansel TR, Lipsky LM, Liu A. Greater diet quality is associated with more optimal glycemic control in a longitudinal study of youth with type 1 diabetes. Am J Clin Nutr 2016;104:81-7.

13 Woo M-H, Park S, Woo J-T, et al. A comparative study of diet in good and poor glycemic control groups in elderly patients with type 2 diabetes mellitus. Korean Diabetes J 2010;34:303-11.

14 Russell LB, Suh D-C, Safford MA. Time requirements for diabetes self-management: too much for many? J Fam Pract 2005;54:52-6.

15 Google. Google COVID-19 community mobility report, 2020. Available: https://www.gstatic.com/covid19/mobility/2020-03-29_ NL_Mobility_Report_en.pdf

16 Cohen S, Kamarck T, Mermelstein R. A global measure of perceived stress. J Health Soc Behav 1983;24:385-96.

17 Little RR, Rohlfing CL, Tennill AL, et al. Effects of sample storage conditions on glycated hemoglobin measurement: evaluation of 
five different high performance liquid chromatography methods. Diabetes Technol Ther 2007;9:36-42.

18 Weykamp C. HbA1c: a review of analytical and clinical aspects. Ann Lab Med 2013;33:393-400.

19 Roncon L, Zuin M, Rigatelli G, et al. Diabetic patients with COVID-19 infection are at higher risk of ICU admission and poor short-term outcome. J Clin Virol 2020;127:104354.

20 Higgins T, Saw S, Sikaris K, et al. Seasonal variation in hemoglobin A1c: is it the same in both hemispheres? J Diabetes Sci Technol 2009;3:668-71.

21 Sohmiya M, Kanazawa I, Kato Y. Seasonal changes in body composition and blood $\mathrm{HbA} 1 \mathrm{c}$ levels without weight change in male patients with type 2 diabetes treated with insulin. Diabetes Care 2004;27:1238-9.

22 Bonora BM, Boscari F, Avogaro A, et al. Glycaemic control among people with type 1 diabetes during Lockdown for the SARS-CoV-2 outbreak in Italy. Diabetes Ther 2020;11:1369-79.

23 Wanner M, Richard A, Martin B, et al. Associations between selfreported and objectively measured physical activity, sedentary behavior and overweight/obesity in NHANES 2003-2006. Int J Obes 2017;41:186-93.
24 Critchley JA, Carey IM, Harris T, et al. Glycemic control and risk of infections among people with type 1 or type 2 diabetes in a large primary care cohort study. Diabetes Care 2018;41:2127-35.

25 Long CA, Fang ZB, Hu FY, et al. SS07. poor glycemic control is a strong predictor of postoperative morbidity and mortality in patients undergoing vascular surgery. J Vasc Surg 2016;63:51S-2.

26 Mor A, Dekkers OM, Nielsen JS, et al. Impact of glycemic control on risk of infections in patients with type 2 diabetes: a populationbased cohort study. Am J Epidemiol 2017;186:227-36.

27 Bornstein SR, Rubino F, Khunti K, et al. Practical recommendations for the management of diabetes in patients with COVID-19. Lancet Diabetes Endocrinol 2020;8:546-50.

28 Stevens PE, Levin A, Kidney Disease: Improving Global Outcomes Chronic Kidney Disease Guideline Development Work Group Members. Evaluation and management of chronic kidney disease: synopsis of the kidney disease: improving global outcomes 2012 clinical practice guideline. Ann Intern Med 2013;158:825-30.

29 World Health Organisation. WHO policy on non-recruitment of smokers or other tobacco users, 2008. Available: https://www.who. int/employment/FAQs_smoking_English.pdf?ua=1 [Accessed 30 May 2020]. 